\title{
A cross-cultural comparison of health-related quality of life and its associated factors among older women in Vietnam and Australia
}

\author{
Tiet-Hanh Dao-Tran ${ }^{1,2^{*}} \mathbb{0}$, Charrlotte Seib ${ }^{3}$, Lee Jones ${ }^{4}$ and Debra Anderson ${ }^{5}$
}

\begin{abstract}
Objective: This study compared health-related quality of life and its associated factors among 305 women in Vietnam and 175 women in Australia aged 60-71. Descriptive analyses, Chi square, independent t-tests, and General Linear Models were used for data analysis.

Results: After controlling for socio-demographics, lifestyles, and chronic diseases, older women in Vietnam had lower levels of physical health but similar levels of mental health to those in Australia. In both populations, chronic disease and diet were associated with physical health; physical activity was related to mental health. In Australia, physical activity, exercise, and Body Mass Index were also associated with physical health; age, alcohol consumption, and sleep were also linked with mental health. In Vietnam, age and marital status were also related to physical health; chronic diseases and diet were also correlated with mental health. These findings suggested that interventions developed in Australia targeting the management of diet and physical activity, may be useful for older women in Vietnam. However, future interventions in Vietnam need to be tailored to account for different age groups, marital status, and the number of chronic diseases experienced. Further investigation into the contributions of cultural factors to healthrelated quality of life is recommended.
\end{abstract}

Keywords: Health-related quality of life, Lifestyles, Chronic diseases, Older women, Cross-cultural comparison

\section{Introduction}

Older women usually reported low levels of health related quality of life (HRQOL) [1-4], raising concern about HRQOL from gender and ageing perspectives. In Vietnam, the number of people aged 60 and over is expected to increase to $20 \%$ of the total population by 2050 [5]. Among this older population, women comprise a higher proportion (58.4\%) [5]. In addition, older women in Vietnam have been subject to various life stressors, which has influenced their lifestyles, health and wellbeing [6]. However, knowledge about HRQOL among older women in Vietnam is still limited.

\footnotetext{
*Correspondence: th.daotran@gmail.com

${ }^{1}$ Centre for Work, Organisation, and Wellbeing, Griffith University, Brisbane, Australia

Full list of author information is available at the end of the article
}

Comparisons of HRQOL and its associated factors across cultures revealed variations among people from different backgrounds [7-9]. These comparisons were conducted among people living in similar populationsfor example: among those living in developed countries together $[7,8]$, among those living in developing countries together [9]-or between people with different cultural background but living in the same context [10]. Similarities and differences in HRQOL and its associated factors between those living in developed countries compared to those living in developing countries-in particular between Vietnam and Australia-is still unclear.

A cross-cultural comparison between Vietnam and Australia might further provide useful directions to help utilize and optimize the resources, which were developed to promote HRQOL in Australia [11, 12] for those in 
Vietnam and this study was conducted to address the following research questions:

1. Are there similarities in HRQOL and its associated factors among older women in Vietnam and Australia?

2. What are the differences in HRQOL and its associated factors among older women in Vietnam and Australia?

\section{Main text \\ Methods}

This cross-sectional study used secondary data from Vietnam and Australia. In Vietnam, data were originally collected in 2013 from 440 female citizens aged 60+ living in urban and rural suburbs in the South of Vietnam; the selection was stratified random [13, 14]. In Australia, data was collected in 2012 from 179 female citizens aged 55-71 living in urban and rural suburbs in South East Queensland. The sample was previously selected at random for participation in longitudinal research conducted from 2001 to 2013 [7, 15, 16]. To achieve a consistent age group among the participants, only data from women aged 60-71 were used for this comparison, including 305 older women in Vietnam and 175 older women in Australia. This sample size is sufficient for the study power statistical analysis.

Data from Vietnam and Australia were measured using the same scales including General Sleep Disturbance Scale [17], and the Short-Form 12 (SF-12) [18]). Selfreport questionnaires were administered during an interview during data collection in Vietnam and; self-reported questionnaires were applied for the Australian data collection. Details of the populations, samples and sampling methods, and measurements have been published elsewhere $[6,7,13-16,19,20]$.

Statistical Package for Social Sciences (SPSS) 23.0 was used for data analysis [21]. Descriptive analyses, Chi square tests and independent t-tests were used to describe the samples' characteristics. General Linear Models (GLM) with purposeful selection approach [22] were also used to compare HRQOL and factors associated with HRQOL among older women in Vietnam and Australia. First, the interactions between factors and nation of residency were examined. Following, bivariate associations were performed to select the associations having $\mathrm{p}<.25$ for an initial multivariable model. All insignificant associations in the initial model were excluded. Next, each excluded variable took turns to come back to the model to check if they were significant and/or were confounders (if they changed the existing model predictor coefficients by $20 \%$ or more). Finally, the interactions among factors in the final model were examined in order to finalize the model. The significance level was set at .05 [23].

\section{Results}

As $45.7 \%$ of participants in Australia did not disclose their income, income were excluded from the study analysis. As seen in Table 1, physical activity were similar between women in Vietnam and Australia ( $p>.05)$. However, participants in Vietnam were slightly younger $(64.72(\mathrm{SD}=3.5)$ vs. $65.88(\mathrm{SD}=2.9))$, less likely to live with their partners ( $58 \%$ vs. $76 \%)$, and be unemployed than Australian participants (34.1\% vs. $22.9 \%)$. Majority of participants in Vietnam had low education levels (72.1\% with primary education or less), while more than one-third of participants in Australia had higher degrees (33.9\% with diploma and university levels).

Participants in Vietnam were less likely to have a healthy diet ( $43.3 \%$ vs. $73.7 \%$ having $\geq 5$ servings of vegetable daily, $42 \%$ vs. $78.9 \%$ having $\geq 2$ servings of fruit daily), consume alcohol (10.2\%vs. $83.4 \%)$ and tobacco ( $1.6 \%$ vs. $33.7 \%)$, practise exercise ( $22.8 \%$ vs. $62.0 \%)$, and be overweight or obese ( $28.2 \%$ vs. $66.7 \%)$, but had a prevalence of sleep disturbance four times higher (38.0\% vs. $9.1 \%)$, and more chronic conditions $(1.61(\mathrm{SD}=.07)$ vs. $1.17(\mathrm{SD}=.07)$ than their Australian counterparts. The prevalence of type 2 diabetes, arthritis, and osteoporosis were similar between the participants in Vietnam and Australia ( $\mathrm{p}>.05)$. The prevalence of hypertension $(50.2 \%$ vs. $33.9 \%)$, heart disease $(26.2 \%$ vs. $1.2 \%)$, and stroke ( $4.6 \%$ vs. $1.2 \%$ ) was significantly higher among the participants in Vietnam. The prevalence of breast cancer $(3.5 \%$ vs. .7\%) and depression (15.2\% vs. .3\%) was significantly higher among the participants in Australia.

Among participants in Vietnam, crude physical health mean scores were $37.7(\mathrm{SD}=13.2)$, and crude mental health mean scores were $54.3(\mathrm{SD}=10.9)$. Among participants in Australia, crude physical health mean scores were 46.4 $(\mathrm{SD}=10.0)$, and crude mental health mean scores were $55.1(\mathrm{SD}=7.4)$.

As seen in Table 1, participants in Vietnam and Australia had a number of differences in sociodemographic characteristics, lifestyles, and the number of chronic diseases, which may confound the comparison of HRQOL using crude values. Thus, GLM was required to adjust the comparison and GLM (Table 2) demonstrates no interactions between sociodemographic characteristics, lifestyles, and the number of chronic diseases and nation of residency ( $p>.05)$. After controlling for personal characteristics, lifestyles, and the number of chronic diseases, Australian participants still had higher levels of adjusted 
Table 1 Sociodemographic characteristics, lifestyles and chronic diseases among older women in Vietnam $(n=305)$ and Australia $(n=175)$

\begin{tabular}{|c|c|c|c|}
\hline & Vietnam, n (\%) & Australia, n (\%) & Differences \\
\hline Age (mean (SD)) & $64.72(3.5)$ & $65.88(2.9)$ & $\mathrm{t}(478)=14.09^{*}$ \\
\hline Married/de facto & $177(58)$ & $130(76)$ & $x^{2}(1)=15.49^{*}$ \\
\hline \multicolumn{4}{|l|}{ Highest education } \\
\hline Primary/less & $220(72.1)$ & $31(18.1)$ & $x^{2}(3)=144.14^{*}$ \\
\hline Junior school & $44(14.4)$ & $60(35.1)$ & \\
\hline Senior school & $26(8.5)$ & $22(12.9)$ & \\
\hline Diploma and university & $15(4.9)$ & $58(33.9)$ & \\
\hline Employed & $104(34.1)$ & $40(22.9)$ & $x^{2}(1)=6.69^{*}$ \\
\hline Having $\geq 5$ servings of vegetable daily & $132(43.3)$ & $129(73.7)$ & $x^{2}(1)=41.52^{*}$ \\
\hline Having $\geq 2$ servings of fruit daily & $128(42.0)$ & $138(78.9)$ & $x^{2}(1)=61.25^{*}$ \\
\hline Alcohol consumption & $31(10.2)$ & $146(83.4)$ & $x^{2}(1)=256.42^{*}$ \\
\hline Tobacco smoking & $5(1.6)$ & $59(33.7)$ & $x^{2}(1)=99.00^{*}$ \\
\hline Physical activity & & & $x^{2}(3)=13.90$ \\
\hline Very active & $55(18.0)$ & $15(8.8)$ & \\
\hline Moderately active & $172(56.4)$ & $115(67.3)$ & \\
\hline Mildly active & $56(18.4)$ & $37(21.6)$ & \\
\hline Sedentary & $22(7.2)$ & $4(2.3)$ & \\
\hline Exercise status & & & $x^{2}(2)=119.15^{*}$ \\
\hline None & $189(62.0)$ & $39(22.8)$ & \\
\hline Not daily & $17(5.6)$ & $112(65.5)$ & \\
\hline Daily & $99(32.5)$ & $20(11.7)$ & \\
\hline Sleep disturbance & $116(38.0)$ & $14(9.1)$ & $x^{2}(1)=42.22^{*}$ \\
\hline $\mathrm{BMl}$ & & & $x^{2}(3)=110.51^{*}$ \\
\hline Underweight & $17(5.6)$ & $1(.6)$ & \\
\hline Normal & $202(66.2)$ & $56(32.7)$ & \\
\hline Overweight & $70(23.0)$ & $42(24.6)$ & \\
\hline Obese & $16(5.2)$ & $72(42.1)$ & \\
\hline Chronic diseases & $1.61(.07)$ & $1.17(.07)$ & $\mathrm{t}(478)=-3.99^{*}$ \\
\hline Hypertension & $153(50.2)$ & 58 (33.9) & $x^{2}(1)=11.73^{*}$ \\
\hline Heart disease & $80(26.2)$ & $2(1.2)$ & $x^{2}(1)=28.26^{*}$ \\
\hline Stroke & $14(4.6)$ & $2(1.2)$ & $x^{2}(1)=3.95^{* *}$ \\
\hline Type 2 diabetes & $36(11.8)$ & $15(8.8)$ & $x^{2}(1)=1.05$ \\
\hline Breast cancer & $2(.7)$ & $6(3.5)$ & $x^{2}(1)=5.40^{* *}$ \\
\hline Arthritis & $155(50.8)$ & $73(42.7)$ & $x^{2}(1)=2.90$ \\
\hline Osteoporosis & $52(17.0)$ & $33(19.3)$ & $x^{2}(1)=.38$ \\
\hline Depression & $1(.3)$ & $26(15.2)$ & $x^{2}(1)=45.32^{*}$ \\
\hline
\end{tabular}

* $\mathrm{p}<.05 ;{ }^{* *} \mathrm{p}<.01$;

physical health than those in Vietnam $(\mathrm{OR}=6.8, \mathrm{p}<.01)$, but similar levels of adjusted mental health ( $\mathrm{p}>.05)$.

In regards to factors associated with HRQOL, the study found that among participants in Vietnam, age, chronic diseases, marital status, and fruit consumption were significantly associated with their physical health $(\mathrm{p}<.01)$, explaining the $16.9 \%$ variance of their physical health scores. Chronic diseases, fruit consumption, and daily physical activity levels were significantly associated with mental health among participants in Vietnam
( $\mathrm{p}<.01$ ), explaining $10.1 \%$ variance of their mental health scores. Among participants in Australia, chronic diseases, vegetable consumption, daily physical activity levels, exercise, and BMI were significantly associated with their physical health scores $(\mathrm{p}<.01)$, explaining $32.1 \%$ variance of their physical health. Age, alcohol consumption, daily physical activity levels, and sleep disturbance were significantly associated with their mental health, explaining $21.4 \%$ variance of their mental health scores. Details about contributions of each 
Table 2 Factors associated HRQOL among older women in Vietnam and Australia $(n=480)$

\begin{tabular}{|c|c|c|c|c|}
\hline Parameters & $\beta$ & Sig & $95 \% \mathrm{Cl}$ & \\
\hline \multicolumn{5}{|l|}{ Physical health } \\
\hline Correct model & & $<.01$ & & \\
\hline Intercept & 67.13 & $<.01$ & 46.96 & 87.29 \\
\hline \multicolumn{5}{|l|}{ Nation of residency } \\
\hline Australians & 6.80 & $<.01$ & 3.55 & 10.04 \\
\hline Vietnamese & Ref & & Ref & Ref \\
\hline Age & -.33 & $<.05$ & -.64 & -.02 \\
\hline Number of chronic diseases & -2.96 & $<.01$ & -3.88 & -2.03 \\
\hline \multicolumn{5}{|l|}{ Fruit consumption } \\
\hline$\geq 2$ servings daily & 4.81 & $<.01$ & 2.56 & 7.06 \\
\hline$<2$ servings daily & Ref & & Ref & Ref \\
\hline \multicolumn{5}{|l|}{ Daily physical activity level } \\
\hline Very active & -.11 & $<.01$ & -3.09 & 2.87 \\
\hline Sedentary & -5.60 & & -10.17 & -1.04 \\
\hline Mildly active & -4.35 & & -7.03 & -1.66 \\
\hline Moderately active & Ref & & Ref & Ref \\
\hline \multicolumn{5}{|l|}{ Exercise status } \\
\hline None & -3.08 & $<.05$ & -5.57 & -.59 \\
\hline Not daily & -3.25 & & -6.70 & .20 \\
\hline Daily & Ref & & Ref & Ref \\
\hline \multicolumn{5}{|l|}{ Sleep disturbance } \\
\hline Yes & -2.89 & $<.05$ & -5.27 & -.51 \\
\hline No & Ref & & Ref & Ref \\
\hline \multicolumn{5}{|l|}{ BMl } \\
\hline Obese & -4.20 & $<.05$ & -7.39 & -1.00 \\
\hline Underweight & -6.28 & & -11.64 & -.92 \\
\hline Overweight & -1.70 & & -4.23 & .83 \\
\hline Normal & Ref & & Ref & Ref \\
\hline Adjusted R square & & & & $28.3 \%$ \\
\hline \multicolumn{5}{|l|}{ Mental health } \\
\hline Correct model & & $<.01$ & & \\
\hline Intercept & 56.25 & $<.01$ & 54.33 & 58.16 \\
\hline \multicolumn{5}{|l|}{ Nation of residency } \\
\hline Australians & .17 & .90 & -2.51 & 2.86 \\
\hline Vietnamese & Ref & & Ref & Ref \\
\hline Number of chronic diseases & -.88 & $<.05$ & -1.63 & -.13 \\
\hline \multicolumn{5}{|l|}{ Fruit consumption } \\
\hline$\geq 2$ servings daily & 3.15 & $<.01$ & 1.30 & 5.00 \\
\hline$<2$ servings daily & Ref & Ref & Ref & Ref \\
\hline \multicolumn{5}{|l|}{ Daily physical activity level } \\
\hline Very active & -5.71 & $<.01$ & -8.19 & -3.22 \\
\hline Sedentary & -5.72 & & -9.60 & -1.85 \\
\hline Mildly active & -.55 & & -2.77 & 1.67 \\
\hline Moderately active & Ref & & Ref & Ref \\
\hline \multicolumn{5}{|l|}{ Alcohol consumption } \\
\hline Yes & -2.55 & .05 & -5.11 & .00 \\
\hline No & Ref & & Ref & Ref \\
\hline Adjusted R square & & & & $8.2 \%$ \\
\hline
\end{tabular}

factors to physical and mental health are presented in Table 3.

\section{Discussion and conclusion}

Comparing HRQOL of older women in Vietnam and Australia, the study found that older women in Vietnam had lower adjusted physical health than those in Australia highlighted a need for more interventions to promote their physical health. The deteriorated physical health of older women in Vietnam may be related to their experience of wars, lack of resources after wars, family care burdens-a primary responsibility of women in this country, chronic diseases [24] and violence experiences [25]. However, their adjusted mental health was similar. This finding is interesting when the dramatic life experiences such as wars, the difficulty of life after wars, and the recent rapid socio-economic changes experienced by older Vietnamese women is taken into consideration. Recent research has shown that exposure to life stressors, and those with adaptive coping strategies [26] and better levels of resilience [27] would be less likely to experience mental health problems. Coping strategies and resilience among older women in Vietnam might be potential explanations for this similarity. However, as the study used an interviewadministered, self-reporting questionnaire to measure mental health, the participants in Vietnam may have under-reported. Therefore, future investigation into coping and resilience among older women in Vietnam is recommended.

Concerning factors associated with HRQOL, in line with current literature, the study delivered the same results for both populations: the number of chronic diseases [28] and diet [29] were associated with physical health; physical activity levels were linked with mental health [30]. This finding suggests that those with more chronic diseases, and a less healthy diet would have a lower level of physical health. Conversely, undertaking regular daily physical activity would had higher levels of mental health. This finding also suggested that interventions to manage chronic diseases, to promote healthy diet, and to moderate physical activity available in Australia can be considered to adopt and modify for Vietnam.

However, first, the relationships between physical activities, exercise, BMI and physical health were inconsistent among women in Vietnam and Australia. Findings from Australian dataset were in line with current literature, suggesting increased physical activity levels [30-32], frequent exercise [33], and normal BMIs [3436] are linked to better physical health. However, data from Vietnam did not support this finding. To explain for this inconsistency, future study should explore how older 
Table 3 Factors associated with HRQOL in relation to nation of residency $(n=305$ and 175)

\begin{tabular}{|c|c|c|c|c|}
\hline Parameters & $\beta$ & Sig & $95 \% \mathrm{Cl}$ & \\
\hline \multicolumn{5}{|c|}{ Physical health/Vietnam $(n=305)$} \\
\hline Correct model & & $<.01$ & & \\
\hline Intercept & 72.06 & $<.01$ & 47.03 & 97.09 \\
\hline Age & -.46 & $<.05$ & -.85 & -.07 \\
\hline Number of chronic diseases & -3.39 & $<.01$ & -4.49 & -2.29 \\
\hline \multicolumn{5}{|l|}{ Marital status } \\
\hline Married/ partnered & -2.78 & $<.05$ & -5.56 & .00 \\
\hline Others & Ref & & Ref & Ref \\
\hline \multicolumn{5}{|l|}{ Fruit consumptions } \\
\hline$\geq 2$ servings daily & 5.09 & $<.01$ & 2.32 & 7.86 \\
\hline$<2$ servings daily & Ref & & Ref & Ref \\
\hline Adjusted R square & & & & $16.9 \%$ \\
\hline \multicolumn{5}{|c|}{ Mental health/Vietnam $(n=305)$} \\
\hline Correct model & & $<.01$ & & \\
\hline Intercept & 56.86 & $<.01$ & 54.51 & 59.22 \\
\hline Number of chronic diseases & -1.35 & $<.05$ & -2.32 & -.37 \\
\hline \multicolumn{5}{|l|}{ Fruit consumptions } \\
\hline$\geq 2$ servings daily & 3.13 & $<.01$ & .72 & 5.54 \\
\hline$<2$ servings daily & Ref & & Ref & Ref \\
\hline \multicolumn{5}{|l|}{ Daily physical activity level } \\
\hline Very active & -7.08 & $<.01$ & -10.25 & -3.92 \\
\hline Sedentary & -4.45 & & -9.20 & .30 \\
\hline Mildly active & -.31 & & -3.50 & 2.87 \\
\hline Moderately active & Ref & & Ref & Ref \\
\hline Adjusted R square & & & & $10.1 \%$ \\
\hline \multicolumn{5}{|c|}{ Physical health/ Australia $(n=175)$} \\
\hline Correct model & & $<.01$ & & \\
\hline Intercept & 57.17 & $<.01$ & 51.85 & 62.49 \\
\hline Number of chronic diseases & -3.51 & $<.01$ & -4.84 & -2.19 \\
\hline \multicolumn{5}{|l|}{ Vegetable consumptions } \\
\hline$\geq 5$ servings daily & 3.06 & $<.05$ & .11 & 6.01 \\
\hline$<5$ servings daily & Ref & & Ref & Ref \\
\hline \multicolumn{5}{|l|}{ Daily physical activity level } \\
\hline Very active & 2.82 & $<.01$ & -1.89 & 7.54 \\
\hline Sedentary & -7.50 & & -15.90 & .90 \\
\hline Mildly active & -4.82 & & -8.00 & -1.64 \\
\hline Moderately active & 2.82 & & -1.89 & 7.54 \\
\hline \multicolumn{5}{|l|}{ Exercise status } \\
\hline None & -7.66 & $<.01$ & -12.38 & -2.95 \\
\hline Not daily & -5.67 & & -9.86 & -1.49 \\
\hline Daily & Ref & & Ref & Ref \\
\hline \multicolumn{5}{|l|}{ BMl } \\
\hline Obese & -4.37 & $<.05$ & -7.43 & -1.30 \\
\hline Underweight & -3.85 & & -20.26 & 12.57 \\
\hline Overweight & -2.84 & & -6.22 & .53 \\
\hline Normal & Ref & & Ref & Ref \\
\hline Adjusted R square & & & & $32.1 \%$ \\
\hline
\end{tabular}

women in Vietnam participate in physical activity and exercise. In addition, as a side note, because the number of obese women in Vietnam is small, the adverse influence of obesity on physical health could not be explored in this study.

A second difference among women in Vietnam and Australia is found in the relationship between age and physical health. As seen in Table 1, older women in Vietnam were less likely to practice exercise than those in Australia. Thus, it is expected that aging could reduce the physical health quicker in Vietnamese sample and so the association became significant in the data analysis. A third difference is found in the relationship between chronic diseases and mental health in the Vietnamese dataset-consistent with current literature [28]-but could not find it in Australian dataset. Fourth, while literature shows that age and alcohol drinking were linked to mental health [37], this association existed only in the Australian dataset. A possible explanation is that the association between age and mental health are inconsistent across the populations. In addition, the prevalence of women drinking alcohol was low in the Vietnamese dataset and the number of those suffering chronic disease among the Australian women was small: significant associations could thus not be found in this low extent. Finally, as personal characteristics, lifestyles, and chronic disease could explain variance of health among older women in Australia better than those in Vietnam $\left(R^{2}=32.1 \%\right.$ vs. $16.9 \%$ for physical health and $21.4 \%$ vs. $10.1 \%$ for mental health), cultural factors may have contributed to the variation of HRQOL and so future research into cultural contribution in HRQOL is recommended.

\section{Limitations}

It is always necessary to justify a study's findings within its limitations. First, this study is cross-sectional and so does not allow for the confirmation of causal relationships like a prospective study design does. Second, as a self-reported questionnaire was used, social desired, reporting and recalling bias may occur. Finally, as data was not selected from a nationwide sample, generalisation of the study's findings is limited to the study populations and the populations having similar characteristics to the study populations. However, the study also have several strengths. First, same measurements were used for both datasets and data were collected at an equivalent period. In addition, the study included socio-demographic characteristics, lifestyles and the number of chronic diseases, and applied advanced statistical approaches in data analysis to control for potential confounders and covariates. These steps improve accuracy of comparison findings [38]. As clinical implications, the study findings suggest that resources to 
Table 3 (continued)

\begin{tabular}{lllll}
\hline \multicolumn{1}{l}{ Parameters } & $\boldsymbol{\beta}$ & Sig & $\mathbf{9 5 \%} \mathbf{C l}$ & \\
\hline $\begin{array}{l}\text { Mental health/ Australia }(\mathrm{n}=175) \\
\text { Correct model }\end{array}$ & & & \\
Intercept & 4.00 & .74 & -19.97 & 27.98 \\
Age & .84 & $<.01$ & .48 & 1.21 \\
Alcohol drinking & & & & \\
Yes & -4.09 & $<.01$ & -6.94 & -1.23 \\
No & Ref & & Ref & Ref \\
Daily physical activity level & & & & \\
$\quad$ Very active & -2.22 & $<.05$ & -5.85 & 1.42 \\
$\quad$ Sedentary & -9.64 & & -16.09 & -3.19 \\
Mildly active & -.82 & & -3.36 & 1.71 \\
$\quad$ Moderately active & Ref & & Ref & Ref \\
Sleep disturbance & & & & \\
$\quad$ Yes & -5.49 & $<.01$ & -9.07 & -1.92 \\
$\quad$ No & Ref & & Ref & Ref \\
Adjusted R square & & & & $21.4 \%$ \\
\hline
\end{tabular}

improve health and wellbeing for older Australia can be adopted for use in Vietnam; future interventions in Vietnam should target healthy diet, moderate physical activity and be tailored for different age groups, marital statuses and the number of chronic diseases experienced for better HRQOL. These interventions will bring more benefits for elderly, married women with more chronic diseases. Findings from this study may also be beneficial for other populations, which have similar characteristics with the study populations.

\section{Abbreviations}

HRQOL: health-related quality of life; SF-12: Short-Form 12; GLM: general linear models; BMI: body mass index; SPSS: statistical package for social sciences.

\section{Authors' contributions}

Study design: THDT, CS, DA; Data collection: THDT; Data analysis: THDT, LJ; Manuscript writing: THDT, LJ. All authors read and approved final manuscript.

\section{Author details \\ ${ }^{1}$ Centre for Work, Organisation, and Wellbeing, Griffith University, Brisbane, Australia. ${ }^{2}$ University of Medicine and Pharmacy at Ho Chi Minh City, Ho Ch Minh City, Vietnam. ${ }^{3}$ School of Nursing and Midwifery, Griffith University, Gold Coast, Australia. ${ }^{4}$ Institute of Health and Biomedical Innovation, Queensland University of Technology, Brisbane, Australia. ${ }^{5}$ School of Nursing and Mid- wifery, Griffith University, Gold Coast, Australia.}

\section{Acknowledgements}

The authors would like to dedicate the study's finding to improve the health and wellbeing of women in Vietnam in the future.

\section{Competing interests}

The authors declare that they have no competing interests.

\section{Availability of data and materials}

The datasets used and/or analysed during the current study available from the corresponding author on reasonable request.

\section{Consent to publication}

Not applicable.

\section{Ethics approval and consent to participate}

The research project gained ethical approvals from the Research Ethics Unit of University of Medicine and Pharmacy at Ho Chi Minh City, Vietnam (No: 192/ DHYD-HD) and Research Ethics Unit, Queensland University of Technology, Australia (No: 1400000256) in accordance with the Declaration of Helsinki. Written informed consents were gained prior to data collection.

\section{Funding}

This research used first author' student allocation for data collection.

\section{Publisher's Note}

Springer Nature remains neutral with regard to jurisdictional claims in published maps and institutional affiliations.

Received: 19 September 2017 Accepted: 7 March 2018

Published online: 13 March 2018

\section{References}

1. Kirchengast S, Haslinger B. Gender differences in health-related quality of life among healthy aged and old-aged Austrians: cross-sectional analysis. Gend Med. 2008;5(3):270-8

2. Milte $C M$, et al. Associations of diet quality with health-related quality of life in older Australian men and women. Exp Gerontol. 2015;64:8-16.

3. Boman $\mathrm{E}_{\text {, et }}$ al. Identifying variables in relation to health-related quality of life among community-dwelling older women: knowledgebase for health-promoting activities. Nordic J Nurs Res. 2015;36(1):20-6.

4. Der-Martirosian C, Cordasco KM, Washington DL. Health-related quality of life and comorbidity among older women veterans in the United States. Qual Life Res. 2013;22(10):2749-56.

5. United Nations. World Population Prospects: The 2010 Revision. 2011. Department of Economic and Social Affairs, Population Division. http:// esa.un.org/wpp/population-pyramids/population-pyramids.htm. Accessed 20 Apr 2013.

6. Dao-Tran TH, Anderson D, Seib C. How life stressors influence modifiable lifestyle factors, depressive symptoms, and physical and mental health among Vietnamese older women? BMC Psychiatry. 2017;17(1):232.

7. Anderson DJ, Yoshizawa T. Cross-cultural comparisons of healthrelated quality of life in Australian and Japanese midlife women: the Australian and Japanese Midlife Women's Health Study. Menopause. 2007;14(4):697-707.

8. Franco $\mathrm{OH}$, et al. Cross-cultural comparison of correlates of quality of life and health status: the whitehall ii study (UK) and the Western New York Health Study (US). Eur J Epidemiol. 2012;27(4):255-65.

9. Nilsson J, et al. Health-related quality of life in old age: a comparison between rural areas in Bangladesh and Vietnam. Asia Pac J Public Health. 2012;24(4):610-9.

10. Yang YM, Wang HH. Cross-cultural comparisons of health-related quality of life between Taiwanese women and transnational marriage Vietnamese women in Taiwan. J Nurs Res. 2011;19(1):44-52.

11. Foottit J, Anderson D. Associations between perception of wellness and health-related quality of life, comorbidities, modifiable lifestyle factors and demographics in older Australians. Australas J Ageing. 2012;31(1):22-7.

12. Emmanuel EN, Sun J. Health related quality of life across the perinatal period among Australian women. J Clin Nurs. 2014;23(11-12):1611-9.

13. Dao-Tran TH, Seib C. Prevalence and correlates of sleep disturbance among older women in Vietnam. J Clin Nurs. 2017.

14. Dao-Tran TH, Anderson D, Seib C. The Vietnamese version of the Perceived Stress Scale (PSS-10): translation equivalence and psychometric properties among older women. BMC Psychiatry. 2017;17(1):53. 
15. Seib C, et al. Stress, lifestyle, and quality of life in midlife and older Australian women: results from the stress and the health of women study. Womens Health Issues. 2014;24(1):e43-52.

16. Seib C, et al. Predictors of mental health in post-menopausal women: results from the Australian healthy aging of women study. Maturitas. 2013;76(4):377-83.

17. Lee KA. Self-reported sleep disturbances in employed women. Sleep. 1992;15:493-8.

18. Jenkinson C, et al. A shorter form health survey: can the SF-12 replicate results from the SF-36 in longitudinal studies? J Public Health Med. 1997;19(2):179-86.

19. Xu Q, Anderson D, Courtney M. A longitudinal study of the relationship between lifestyle and mental health among midlife and older women in Australia: findings from the healthy aging of women study. Health Care Women Int. 2010;31(12):1082-96.

20. Dao-Tran TH, Seib C. Prevalence and correlates of sleep disturbance among older women in Vietnam. J Clin Nurs. 2017.

21. Armonk. IBM SPSS Statistics 2013. NY: IBM Corp.

22. Bursac $Z$, et al. Purposeful selection of variables in logistic regression. Sour Code Biol Med. 2008:3(1):17.

23. Pallant J. SPSS survival manual: a step by step guide to data analysis using SPSS. 4th ed. Milton Keynes: Open University Press; 2010

24. Mwangi J, Kulane A, Van Hoi L. Chronic diseases among the elderly in a rural Vietnam: prevalence, associated socio-demographic factors and healthcare expenditures. Int J Equity Health. 2015;14:134.

25. Vung ND, Ostergren P-O, Krantz G. Intimate partner violence against women, health effects and health care seeking in rural Vietnam. Eur J Pub Health. 2009;19(2):178-82.

26. Kirby R, Shakespeare-Finch J, Palk G. Adaptive and maladaptive coping strategies predict posttrauma outcomes in ambulance personnel. Traumatology. 2011;17(4):25-34

27. Streb M, Häller P, Michael T. PTSD in paramedics: resilience and sense of coherence. Behav Cogn Psychother. 2014;42(4):452-63.
28. Der-Martirosian C, Cordasco KM, Washington DL. Health-related quality of life and comorbidity among older women veterans in the United States. Qual Life Res. 2013;22(10):2749-56.

29. Keller $\mathrm{HH}$. Nutrition and health-related quality of life in frail older adults. J Nutr Health Aging. 2004;8(4):245-52.

30. Dale CE, et al. Predictors of patterns of change in health-related quality of life in older women over 7 years: evidence from a prospective cohort study. Age Ageing. 2013;42:312-8.

31. Heesch $\mathrm{KC}$, et al. Dose-response relationships between physical activity, walking and health-related quality of life in mid-age and older women. J Epidemiol Community Health. 2012;66(8):670-7.

32. Gomez LF, et al. Physical activity and health-related quality of life among adult women in Cali, Colombia: a cross-sectional study. Qual Life Res. 2013;22(9):2351-8

33. Karinkanta $\mathrm{S}$, et al. Effects of exercise on health-related quality of life and fear of falling in home-dwelling older women. Aging Phys Act. 2012;20(2):198-214

34. Yan $\mathrm{LL}$, et al. BMI and health-related quality of life in adults 65 years and older. Obes Res. 2004;12(1):69-76.

35. Renzaho A, Wooden M, Houng B. Associations between body mass index and health-related quality of life among Australian adults. Qual Life Res. 2010;19(4):515-20.

36. Pinto AM, et al. The effect of weight loss on changes in health-related quality of life among overweight and obese women with urinary incontinence. Qual Life Res. 2012;21(10):1685-94.

37. Byles J, et al. A drink to healthy aging: the association between older women's use of alcohol and their health-related quality of life. J Am Geriatr Soc. 2006;54(9):1341-7.

38. Peterson RA. Problems in comparative research: the example of omnivorousness. Poetics. 2005;33(5-6):257-82.

\section{Submit your next manuscript to BioMed Central and we will help you at every step:}

- We accept pre-submission inquiries

- Our selector tool helps you to find the most relevant journal

- We provide round the clock customer support

- Convenient online submission

- Thorough peer review

- Inclusion in PubMed and all major indexing services

- Maximum visibility for your research

Submit your manuscript at www.biomedcentral.com/submit
O Biomed Central 